\title{
Energy-Efficient Air-Cooled DX Air-Conditioning Systems with Liquid Pressure Amplification
}

\author{
V. Vakiloroaya and Q.P. Ha \\ School of Electrical, Mechanical and Mechatronic Systems, \\ University of Technology, Sydney, Australia \\ E-mail: vahid.vakiloroaya@engineer.com,quang.ha@uts.edu.au
}

\begin{abstract}
-
The objective of this study is to explore an optimal strategy on energy consumption for a direct expansion (DX) air-conditioning system by using a refrigerant pump in the liquid line to allow the system to operate at a lower condensing pressure. An existing DX rooftop package of a commercial building located in a hot and dry climate zone is used for data collection. The theoretical-empirical modelling approach is used to obtain system model, from which the proposed strategy is formulated. A numerical algorithm is developed to analyse the system transient performance, using an iterative loop. As a minimum pressure differential is required across the expansion device, liquid pressure amplification (LPA) devices can be used on DX systems that operate with fixed head pressure control. They can be fitted to new or existing systems. Results show that the LPA approach is more effective when the ambient temperature is falling, with electricity saving around $25.3 \%$ in average.
\end{abstract}

Keywords -

Energy Saving; Experimental Study; HVAC; Modelling; Liquid Pressure Amplification

\section{Introduction}

Nowadays, heating, ventilation and air conditioning (HVAC) systems typically account for around $40 \%$ of total electricity consumption of buildings [1], attributed mainly for creating peak electricity demand. In recent years, hotter weather has meant the demand for peak energy growing much faster than for the base power. As a result, finding new ways to reduce energy consumption in buildings without compromising comfort and indoor air quality is an ongoing research challenge. One proven way of achieving energy efficiency in the vapour compression refrigeration systems is to reduce the compressor discharge pressure $[2,3]$, which decreases its compression ratio, and in turn, causing to less electricity consumption.
Many studies report that reduced compressor discharge pressures and the corresponding reduction of compression ratios in a refrigeration cycle are advantageous when it comes to HVAC energy saving and increasing its service time. There are, however, some solutions to significantly lower compressor discharge pressures whilst preventing the flash vapour occurrence. For example, pre-cooling the ambient air before it reaches the air-cooled condenser of the vapour compression cooling systems can reduce the condensing temperatures to drop the condensing pressure. $\mathrm{Yu}$ and Chen [4] investigated how the coefficient of performance (COP) of air-cooled chillers can be improved by using mist pre-cooling. They estimated around $18 \%$ decrease in the annual electricity usage could be achieved with mist pre-cooling of air entering the air-cooled condenser of chiller, used to serve a hotel in a sub-tropical climate. The application of LPA to aircooled air conditioning systems can assist in achieving a considerable reduction in compressor discharge pressure. LPA can be realised with a hermetically-sealed, magnetically-driven liquid refrigerant pump installed in the liquid line between the condenser and expansion valve. The LPA pump increases the pressure of the liquid refrigerant before it enters the expansion valve. This method allows the condensing temperature to fluctuate with ambient temperature changes, and hence, reducing the condensing pressure and lowering overall energy consumption.

The compressor is the largest power consumer in a vapour compression system. As a result, many previous studies have investigated the influence of various technologies on the compressor performance to enhance the operating and energy efficiency of vapour compression refrigeration systems [5]. However, compared with a water-cooled air conditioning system, air-cooled cycles are less energy-efficient. Wang et al. [6] studied the impact of two performance improvement techniques applied to a compressor with different refrigerants. The first technique involved cooling the compressor motor via external means, while the second used isothermal compression achieved by transferring heat from the compressor chamber. Their results 
showed that these approaches could reduce the power consumption of the compressor by up to $16 \%$ for external cooling and $14 \%$ for the isothermal technique. In [7], the system performance of an R410A inverter air-conditioner could be improved using an evaporativecooled condenser, increasing the tested system's COP by $18.32 \%$. A comparative study of heat recovery and floating condensing temperature techniques was carried out by Arias and Lundqvist [8] to show that with a condensing temperature of $40^{\circ} \mathrm{C}$, a system using the floating condensing temperature technique could achieve a $50 \%$ improvement in energy savings when compared to a conventional refrigeration system.

The objective of this study is to explore the influence of an optimal strategy on energy consumption of an existing direct expansion air conditioning system. For this purpose, an actual air-cooled rooftop package air conditioning system of a real-world commercial building located in a hot and dry climate zone in the northern hemisphere was used for experimentation and data collection. Field tests were conducted to quantify and determine the system variables. Mathematical models were obtained by using a theoretical-empirical approach, and the proposed strategy was formulated on the basis of these models. A transient simulation software package, TRNSYS 16 [9] was used to predict the HVAC energy usage. From the TRNSYS codes and real-world test data, a simulation module for the cooling plant was developed and embedded in the software. Performance predictions were then compared with actual performance measurements to verify the models and to compare the strategy performance. Findings reported in this paper show that energy saving of $42 \%$ is possible using the proposed method.

\section{System modelling}

Many models for DX rooftop package air conditioning system have been developed using various principles. In the following, a combined theoreticalempirical approach will be developed for componentwise modelling. A single stage vapour compression direct expansion air conditioning system consists of four major components, namely a rotary scroll compressor, an air-cooled condenser, an expansion valve and a DX evaporator. Figure 1 shows a schematic block diagram of the conventional and developed DX air conditioning system while their pressure-enthalpy diagram is depicted in Fig. 2. In a conventional system, the cycle starts with a mixture of liquid and vapour refrigerant entering the evaporator (point 1). In the following, notations used in the analysis are given in the nomenclature following Section 5. The DX evaporator used in the plant is of a rectangular finned tube type of heat exchanger, in which both the refrigerant and air are

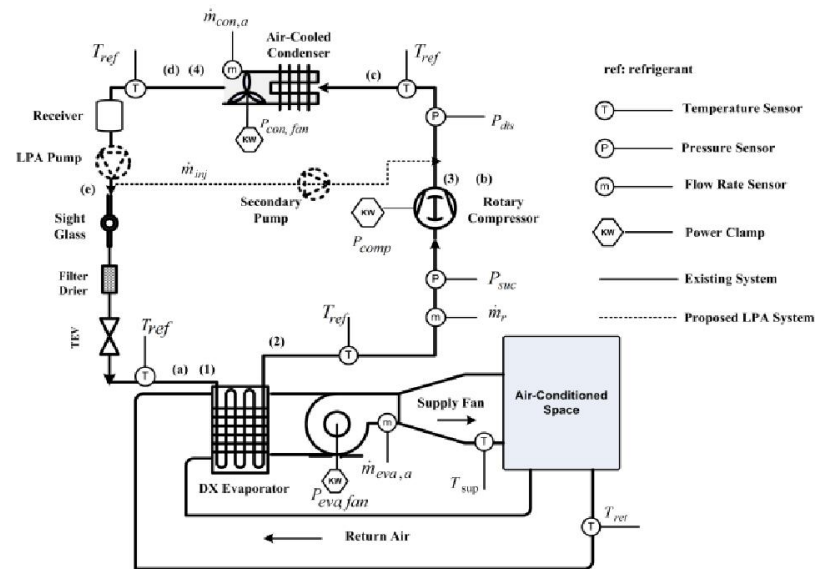

Figure 1. DX schematic diagram

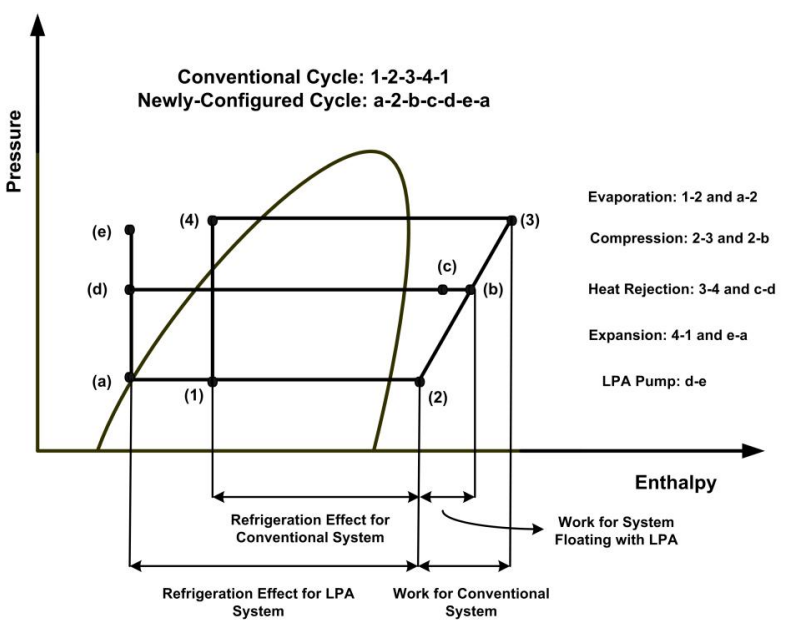

Figure 2. p-h diagram of the conventional and LPA DX air conditioning system

assumed to be counter-flow. When heat from warm air is absorbed by a DX evaporator coil, the refrigerant is changed from liquid to gas and becomes superheated at the evaporator exit. Superheat is required to prevent slugs of the liquid refrigerant from reaching the compressor to cause any serious damage. The supply air temperature can be estimated by:

$T_{\text {sup }}=T_{e v a, a, i}-\frac{\dot{m}_{r}}{\dot{m}_{\text {eva }, a} C_{p, a}}\left(h_{2}-h_{1}\right)$,

in which the enthalpy of the refrigerant leaving the DX evaporator, $h_{2}$, is determined as:

$h_{2}=h_{\text {eva }, r, s a t}+C_{p, r}\left(T_{\text {eva }, r, s h}-T_{\text {eva }, r, s a t}\right)$,

where $T_{\text {evar,sh }}$ is the temperature of the superheated vapour refrigerant leaving the evaporator to be measured during the experimentation. The input power 
of the evaporator fan, which is adjusted for part load operating conditions, is proposed as a function of the refrigerant mass flow rate, building cooling load and supply air temperature as:

$$
\begin{aligned}
& P_{\text {eva, fan }}=a_{0}+a_{1} \dot{m}_{r}+a_{2} \dot{m}_{r}^{2}+a_{3} T_{\text {sup }}+a_{4} T_{\text {sup }}^{2} \\
& +a_{5} Q_{b}+a_{6} Q_{b}^{2}+a_{7} \dot{m}_{r} T_{\text {sup }}+a_{8} \dot{m}_{r} Q_{b}+a_{9} T_{\text {sup }} Q_{b},
\end{aligned}
$$

where coefficients $a_{0}$ to $a_{9}$ are constant to be determined by curve-fitting of experimental data.

The superheat vapour then enters the compressor, at point 2, where an increasing pressure will in turn increase the temperature. In this study, a steady-state polytropic compression is considered, assuming the compressor speed reaches its specified speed instantaneously. The compressor mass flow rate is given by:

$$
\dot{m}_{r}=\frac{V_{D} \eta_{v}}{v_{s u c}}
$$

where $\eta_{v}$ is the volumetric efficiency of the compressor and can be obtained by:

$\eta_{v}=0.92-0.08 \times\left[\left(\frac{p_{\text {dis }}}{p_{\text {suc }}}\right)^{\frac{1}{k}}-1\right]$.

The work of compression is obtained by:

$W_{\text {in }}=\frac{\dot{m}_{r}}{\eta_{\text {comp }}} p_{\text {suc }} v_{\text {suc }}\left(\frac{k}{k-1}\right)\left(\left(\frac{p_{\text {dis }}}{p_{\text {suc }}}\right)^{\left(\frac{k-1}{k}\right)}-1\right)$.

The empirical expression to determine the compressor power consumption $P_{\text {comp }}$ is proposed as:

$$
\begin{aligned}
& P_{\text {comp }}=b_{0}+b_{1} T_{\text {suc }}+b_{2} T_{\text {dis }}+b_{3} T_{\text {suc }}^{2}+b_{4} T_{\text {suc }} T_{\text {dis }} \\
& +b_{5} T_{d i s}^{2}+b_{6} T_{\text {suc }}^{3}+b_{7} T_{\text {suc }}^{2} T_{d i s}+b_{8} T_{\text {suc }} T_{d i s}^{2}+b_{9} T_{d i s}^{3},
\end{aligned}
$$

where coefficients $b_{0}$ to $b_{9}$ are constant, obtained by curve-fitting of the collected data.

The refrigerant enthalpy leaving the compressor is calculated as:

$$
h_{3}=\frac{\dot{m}_{r} h_{2}+W_{i n}}{\dot{m}_{r}} \text {. }
$$

The required heat rejection capacity of the condenser is obtained from:

$$
Q_{\text {con }}=A U \Delta T_{m},
$$

where $\Delta T_{m}$ is the mean temperature difference given by:

$$
\Delta T_{m}=\frac{T_{\text {con }, a, o}-T_{a m b}}{\ln \left(\frac{T_{\text {cond }}-T_{a m b}}{T_{\text {cond }}-T_{\text {con }, a, o}}\right)},
$$

and

$\frac{1}{A U}=\frac{1}{\eta_{o} \alpha_{a} A_{o}}+\frac{1}{2} \ln \left(\frac{d_{o}}{d_{i}}\right) \frac{d_{o}}{A_{w} k_{w}}+\frac{1}{\alpha_{r} A_{i}}$,

in which $A_{o}$ is the total heat transfer area, i.e.:

$$
A_{o}=A_{f}+A_{b},
$$

and $A_{f}$ and $A_{b}$ are areas respectively of the fin and bare tube:

$$
\begin{aligned}
& A_{b}=\left(\frac{D-t_{f}}{D \times V T S} \pi d_{o}\right) A_{f r} N_{\text {row }}, \\
& A_{f}=\left(\frac{2}{D}\left(H T S-\frac{\pi d_{0}^{2}}{4 \times V T S}\right)\right) A_{f r} N_{\text {row }} .
\end{aligned}
$$

The surface effectiveness is given by:

$\eta_{o}=1-\frac{A_{f}}{A_{o}}\left(1-\eta_{f}\right)$

in which the fin efficiency $\eta_{f}$ can be determined by approximation as described in Schmidt [10]:

$\eta_{f}=\frac{\tanh (m r \phi)}{m r \phi}$

where

$m=\sqrt{\frac{2 \alpha_{a}}{k_{f} t_{f}}}$

$\phi=\left(\frac{R_{e q}}{r}-1\right)\left[1+0.35 \ln \left(\frac{R_{e q}}{r}\right)\right]$ 


$$
\frac{R_{e q}}{r}=0.635 \frac{V T S}{r}\left(\frac{V T S}{2 \sqrt{\left(\frac{V T S}{2}\right)^{2}+\left(\frac{H T S}{2}\right)^{2}}}-0.3\right)^{0.5}
$$

The refrigerant side heat transfer coefficient can be calculated in two cases:

- $\quad$ For single-phase section [11]:

for $\operatorname{Re}_{d}<3500$,

$N u=1.11\left(\operatorname{Re}_{d}\right)^{0.21} \operatorname{Pr}^{1 / 3}=\frac{\alpha_{r} d_{i}}{k_{r}}$

for $3500 \leq \operatorname{Re}_{d} \leq 6000$,

$N u=3.52 \times 10^{-7}\left(\operatorname{Re}_{d}\right)^{2.03} \operatorname{Pr}^{1 / 3}=\frac{\alpha_{r} d_{i}}{k_{r}}$

for $\operatorname{Re}_{d}>6000$,

$N u=0.22\left(\operatorname{Re}_{d}\right)^{0.615} \operatorname{Pr}^{1 / 3}=\frac{\alpha_{r} d_{i}}{k_{r}}$.

- $\quad$ For two-phase section [12]:

$\alpha_{t p}=\alpha_{l}\left[(1-x)^{0.8}+\frac{3.8 x^{0.76}(1-x)^{0.04}}{\operatorname{Pr}^{0.38}}\right]$,

where $\alpha_{l}$ is the heat transfer coefficient of liquid refrigerant calculated from the Dittus and Boelter correlation [13]:

$$
N u=0.023 \operatorname{Re}_{d}^{0.8} \operatorname{Pr}^{0.3} .
$$

The heat transfer coefficient on the air side is expressed as:

$\alpha_{a}=\frac{j G_{a, \max } C_{p, a}}{\operatorname{Pr}^{2 / 3}}$,

where the Colburn factor $j$ can be determined from the correlation of McQuiston and Parker [14].

The pressure drop on the air side of the condenser coil is given as [15]:

$$
\Delta p_{\text {con }, a}=\frac{G_{a}^{2}}{2 \rho_{i}}\left[f_{a} \frac{A_{o}}{A_{\min }} \frac{\rho_{i}}{\rho_{\text {avg }}}+\left(1+\sigma^{2}\left(\frac{\rho_{i}}{\rho_{o}}-1\right)\right]\right. \text {, }
$$

in which the air side friction factor is calculated as:

$$
f_{a}=0.0267 \operatorname{Re}_{c}^{F_{1}}\left(\frac{V S T}{H T S}\right)^{F_{2}}\left(\frac{P_{f}}{d_{c}}\right)^{F_{3}},
$$

where

$$
F_{1}=-0.764+0.739\left(\frac{V S T}{H T S}\right)+0.177\left(\frac{P_{f}}{d_{c}}\right)-\frac{0.00758}{N_{\text {row }}}
$$

$F_{2}=-15.689+\frac{64.012}{\ln \left(\operatorname{Re}_{c}\right)}$,

$F_{3}=1.696-\frac{15.695}{\ln \left(\operatorname{Re}_{c}\right)}$.

The power consumption of the condenser fan then can be expressed as:

$$
P_{\text {con }, \text { fan }}=\frac{\Delta p_{\text {con }, a} V_{c o n, a}}{\eta_{c o n, f a n}} .
$$

In a conventional vapour compression refrigeration system, the condensing pressure is designed to allow refrigerant condensation at high ambient temperature. In this way, the energy may be wasted in partial loads when the ambient temperature is low and a high condensing temperature is not required. In this study a refrigerant pump is incorporated after the condenser's receiver in the liquid line to preserve the high pressure differential across the expansion valve. Consequently, the condenser pressure can be adjusted with variation of the ambient temperature to result in a lower discharge pressure during the partial load period, and in turn, to reduce the compressor power consumption. Therefore, the compressor head pressure is reduced from point (3) to point (b) at steady state conditions, as shown in Fig. 2. In addition, a small amount of the liquid sub-cooled refrigerant is injected into the compressor discharge line using a secondary pump. Therefore, the temperature of the discharge refrigerant gas entering the condenser is decreased to reduce the difference between the ambient and condensing temperature, and thus, to increase the efficiency of the condenser. This is shown in Fig. 2 by moving point (b) to point (c). The superheated refrigerant then enters the air-cooled condenser, where a final reduction in the refrigerant temperature takes place and causes it to de-superheat, and thus, the refrigerant liquid is sub-cooled as it enters the expansion valve. As a result, refrigeration effect of the evaporator is increased, enabling the system to deal with a higher load demand. As illustrated in Fig. 2, this is occurred by replacing point (1) to point (a) in the refrigeration cycle. 
In this study, $5 \%$ of the total refrigerant mass flow rate is injected to the discharge line of the compressor at each iteration loop of the simulation. Therefore, the temperature of the refrigerant entering and leaving the condenser in the LPA system can be determined by:

$$
\begin{aligned}
& h_{c}=\frac{h_{b}+0.05 h_{i n j}}{1.05}, \\
& h_{d}=h_{c}-\frac{\dot{m}_{c o n, a} C_{p, a}}{\dot{m}_{r}}\left(T_{\text {cond }}-T_{a m b}\right) .
\end{aligned}
$$

The input power of the condenser fan is proposed as a function of the refrigerant mass flow rate and ambient dry-bulb temperature as:

$$
\begin{aligned}
& P_{c o n, f a n}=c_{0}+c_{1} \dot{m}_{r}+c_{2} \dot{m}_{r}^{2}+c_{3} T_{a m b} \\
& +c_{4} T_{a m b}^{2}+c_{5} \dot{m}_{r} T_{a m b},
\end{aligned}
$$

where coefficients $c_{0}$ to $c_{5}$ are constant to be determined by curve-fitting of the experimental data.

The high pressure sub-cooled refrigerant flows through the expansion valve, at point (d), which serves to reduce its pressure. The expansion valve is a refrigerant flow control device that adjusts the quantity of the liquid refrigerant entering the evaporator, and thus regulates the refrigerant superheat temperature leaving the evaporator. Furthermore, by this method the refrigeration effect of the evaporator is increased, enabling the system to deal with a higher load demand. However, due to a minimum pressure difference across the expansion valve required for proper operation of the thermostatic expansion valve, the amount of the discharge pressure to be reduced is limited. Therefore, the energy saving potential here is a function of the minimum acceptable pressure differential across the expansion valve and the ambient temperature. For an isenthalpic process in the expansion valve, we have $h_{4}=h_{1}$ in conventional systems, or $h_{d}=h_{a}$ in this proposed LPA system.

\section{Case Study}

The proposed strategy is modelled on the existing DX rooftop package unit serving an office building as our experimental set-up. The floor area of the airconditioned room was 325 square meters with a height of 3 meters. The building is open from 8.00 am to 10.00 $\mathrm{pm}$. The walls, windows, floor and roof are modelled according to ASHRAE [16]. More details about the building materials and internal loads can be found in [17]. The weather data that drive project simulations are based on a typical meteorological year. The data file distributed with TRNSYS 16 is generated using "Meteonorm" including Synthetic hourly weather data, including information about the month of the year, hour of the month, direct normal solar radiation, global solar radiation, dry-bulb temperature, humidity ratio and wind speed.

The DX rooftop package comprises an electrostatic expansion valve, a DX evaporator, an air-cooled condenser and a scroll compressor with nominal capacity of $52.5 \mathrm{~kW}$. The working fluid is refrigerant R22. The evaporative temperature at designed conditions is set to be $4.4^{\circ} \mathrm{C}$. Supply air flow rate is $8748 \mathrm{~m}^{3} / \mathrm{h}$ at designed conditions. The designed electric power input of the evaporator variable speed fan at maximum air flow rate is $1.3 \mathrm{~kW}$. Heat rejection capacity of the air-cooled condenser is designed to control the condensing temperature at $50^{\circ} \mathrm{C}$. The nominal air flow rate of the condenser variable air volume fan is $12400 \mathrm{~m}^{3} / \mathrm{h}$ and its rated power input is $1.1 \mathrm{~kW}$

\subsection{Experimental Set-Up}

Figure 3 shows the experimental set-up. High precision sensors/transducers were used for measuring all operating variables. The temperature sensor for the supply and return air is of platinum resistance type with accuracy of $\pm 0.1^{\circ} \mathrm{C}$. The refrigerant mass flow rate passing through the compressor is measured by a Coriolis mass flow meter with accuracy $\pm 0.1 \%$. Four platinum resistance thermometers of PT100 type with a calibrated accuracy of $\pm 0.5^{\circ} \mathrm{C}$ for a temperature range from $-50^{\circ} \mathrm{C}$ to $+260^{\circ} \mathrm{C}$ are used to measure the refrigerant temperature before and after of each component. These sensors are in direct contact with the refrigerant to achieve high accuracy. Two pressure transmitters with a calibrated accuracy of $1 \%$ are respectively installed in the suction line and discharge line.

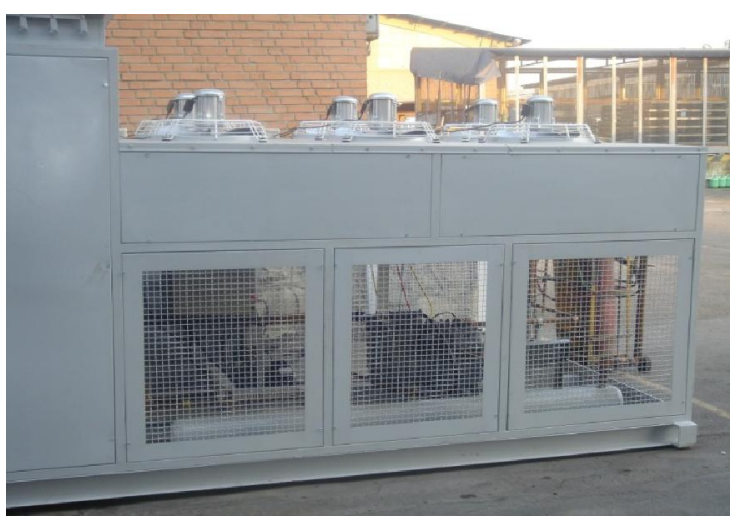

Figure 3. Experimented DX rooftop package 
The pressure measuring range for the suction line is from 0 to $2000 \mathrm{kPa}$ and for the discharge line from 0 to $3500 \mathrm{kPa}$. The ambient temperature is monitored by a digital thermometer of accuracy $\pm 0.8^{\circ} \mathrm{C}$. Electric component powers are measured by a digital power clamp of accuracy $\pm 3.5 \%$. All measurement signals are acquired with a 20-minute sampling time. Therefore a total 3234 points of the system's power consumption and other variables were collected. Data were logged at the test system using history sheets available in the system measuring tools.

\subsection{Model Validation}

The mathematical model of the system components is coded into the fully integrated visual interface known as TRNSYS simulation studio using FORTRAN. Under real conditions there are many factors that can influence the HVAC system performance. In this study, all dimensions of the system components and dimension of connected pipes are included in the program code. The experimentally obtained data were entered through a dedicated visual interface. The model included a subroutine to evaluate thermodynamic properties of refrigerant R22. This simulation code was then used to obtain parameters of main interest such as the evaporative and condensing temperature, condensing pressure, temperature of refrigerant leaving the compressor, temperature of refrigerant entering and leaving the condenser and liquid line temperature as well as power consumption of the compressor, evaporator variable air volume (VAV) fan, and condenser VAV fan.

According to the data provided by field tests, the corresponding coefficients of the models are obtained by regression techniques using MINITAB [18]. The Rsquared value of each model indicates a good fit. Regression process yields coefficients according to variations of the overall energy consumption. These coefficients for the rooftop package used in this study are described in [17], where the integrated simulation tool was validated by comparing the predicted and measured total power consumption of the system for a week in mid-summer.

\section{Results and Discussion}

Having described the specification of plant and developed strategy, the simulation is run with a time interval of 20 minutes, i.e. equal to the monitoring time step in the real test process. The cooling load is calculated prior to the simulation performed with TRNSYS. The references for indoor temperature and relative humidity during the cooling load calculation were set respectively at $23^{\circ} \mathrm{C}$ and $50 \%$. The peak cooling load is estimated at $36.7 \mathrm{~kW}$. As mentioned before, the LPA technique allows the compressor to be run at a lower delivery pressure, with the pump providing the required stable pressure for the expansion valve and thus the condensing pressure can float with ambient temperatures.

\subsection{Performance Prediction}

The variation of condensing temperature and condensing pressure, discharge temperature, evaporative temperature and temperature of refrigerant in liquid line are discussed in this section. The condensing temperature profile is shown in Fig. 4, where it can be seen that the condensing temperature in a conventional system is maintained relatively constant at an average value of $43^{\circ} \mathrm{C}$ while in the system floating with LPA, it varies in a larger range. The reason is that the system floating with LPA can operate at a lower condensing temperature as a result of decreasing the compressor head pressure. Figure 5 shows the variation of compressor discharge pressure and discharge temperature for both the conventional and LPA system. The results show that the average refrigerant discharge pressure drops from $1750 \mathrm{kPa}$ to $1170 \mathrm{kPa}$ after using an LPA pump whilst the refrigerant discharge temperature is reduced from $81.5^{\circ} \mathrm{C}$ to $62.3^{\circ} \mathrm{C}$.

Nevertheless, results show that changes in the condensing temperature do not have a considerable effect on the evaporative temperature, as shown in Fig. 6. This is because the variation of the evaporative pressure is dependent on the heat transfer rate and fairly insensitive to both the condensing temperature and pressure.

The temperature of refrigerant in the liquid line in the proposed LPA system is notably less than that for the conventional system, as shown in Fig. 7. The reason is that the sub-cooled refrigerant injected into the discharge line quickly flashes and reduces the temperature of the superheated refrigerant vapour. As indicated in Fig. 7, the average temperature of the refrigerant at the liquid line after floating the condensing pressure by LPA pump is dropped from $31^{\circ} \mathrm{C}$ to $17^{\circ} \mathrm{C}$. The drop of the refrigerant temperature entering the condenser leads to a reduction in refrigerant temperature leaving the condenser. This means a more substantial sub-cooling at the condenser outlet and therefore a reduction of the refrigerant enthalpy entering the evaporator. This enhances the system refrigeration effect and thereby its COP. Simulation results show that the average COP of the system floating with LPA, at various evaporative temperatures, is greater than that under the commonly-used designs, as shown in Fig. 8. 


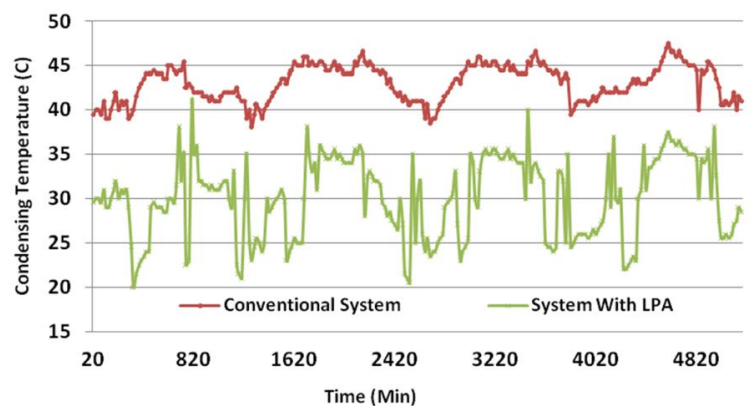

Figure 4. Condensing temperature

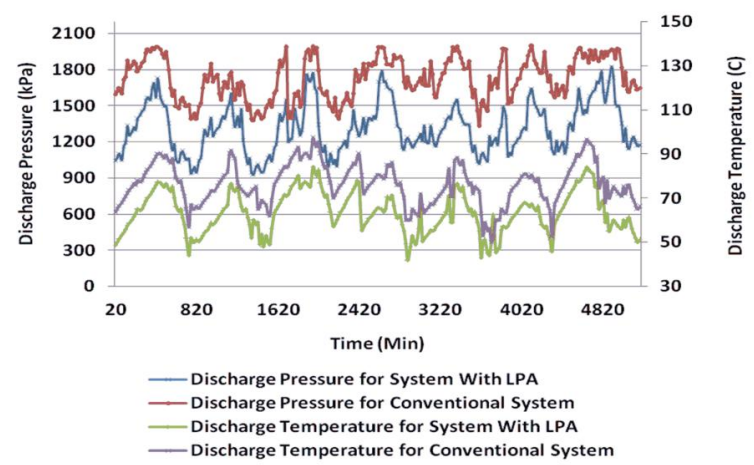

Figure 5. Discharge pressure and temperature

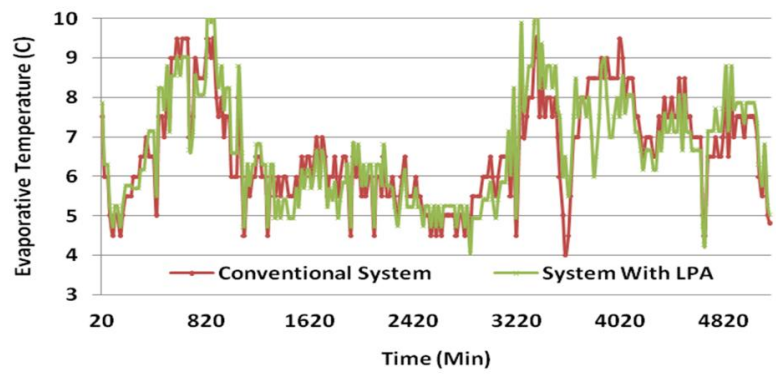

Figure 6. Evaporative temperature

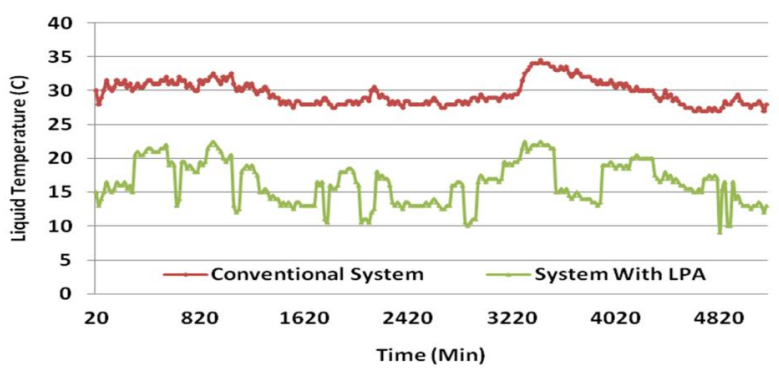

Figure 7. Liquid refrigerant temperature

The comparison study using simulation results indicated significant energy saving potential in steadystate conditions. The enthalpy of the refrigerant entering the condenser with and without the proposed configuration is found to reduce from $440.16 \mathrm{~kJ} / \mathrm{kg}$ to $432.78 \mathrm{~kJ} / \mathrm{kg}$.
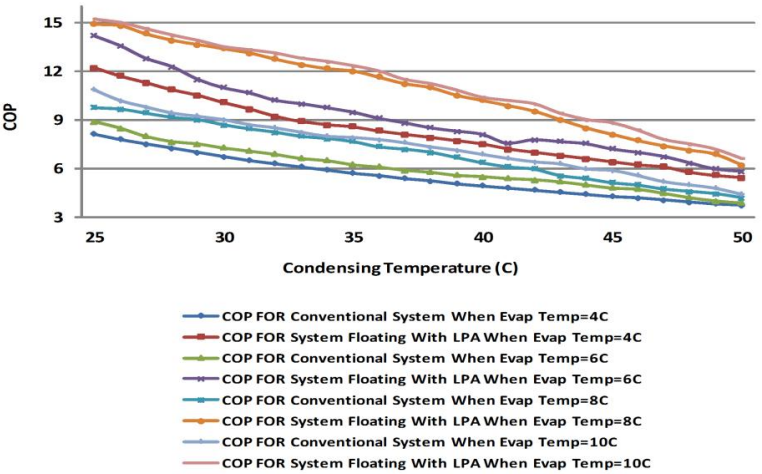

Figure 8. COP comparison

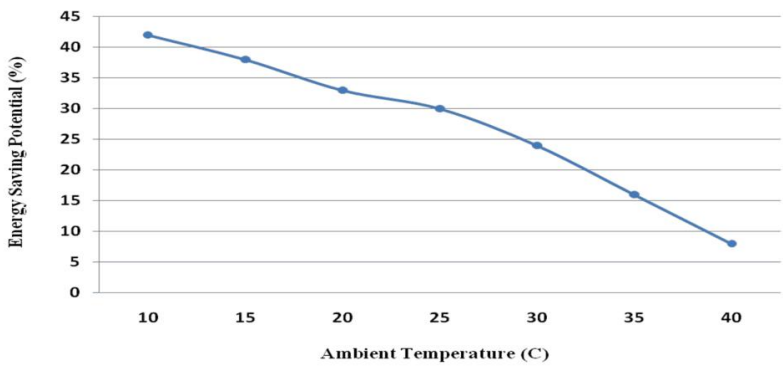

Figure 9. Energy saving vs. ambient temperature

Furthermore, temperature of the refrigerant entering the condenser is decreased from $63.05^{\circ} \mathrm{C}$ to $48.71^{\circ} \mathrm{C}$, leading to a temperature reduction of the refrigerant leaving the condenser from $30^{\circ} \mathrm{C}$ to $17^{\circ} \mathrm{C}$. This temperature reduction yields to lessen the displacement volume of the compressor from $0.0127 \mathrm{~m}^{3} / \mathrm{s}$ to 0.0116 $\mathrm{m}^{3} / \mathrm{s}$ to drop the compressor work. Moreover, the condensing temperature in this condition decreases from $35^{\circ} \mathrm{C}$ to $25^{\circ} \mathrm{C}$, causing a reduction of condensing pressure from $1355 \mathrm{kPa}$ to $1044 \mathrm{kPa}$. Therefore, due to a discharge pressure drop, the compressor pressure ratio becomes lower to result in an additional diminution of the compressor work. In the steady state, compressor power consumption for a conventional cycle and the LPA system are respectively $13.9 \mathrm{~kW}$ and $9.04 \mathrm{~kW}$, indicating $34.9 \%$ energy savings. Furthermore, enthalpy of the refrigerant entering the evaporator by using the LPA system is nearly $6.85 \%$ less than of a conventional system, i.e. more refrigeration effect for the LPA system evaporator. However, simulation results in the designed steady state show a less energy saving potential due to a high ambient temperature in that condition. It means that the potential of energy savings using the LPA technique is exceedingly dependent on the ambient temperature and would increase with dropping the ambient temperature, as shown in Fig. 9. Moreover, according to results the amount of energy saving for the designed steady-state condition is $8 \%$, almost due to more sub-cool temperature created by liquid refrigerant injection to the discharge line rather than floating the 
condensing pressure. As a result, the energy saving potential of the LPA system depends more on floating the condensing temperature at a low ambient temperature, and more on increasing the sub-cool temperature at a high ambient temperature.

\subsection{Energy Analysis}

To estimate the energy saving potential of the LPA system over the summer, its energy consumption is compared with that of a conventional rooftop package. The hourly power usage of both systems is shown in Fig. 10 , as obtained from TRANSYS, indicating nearly $25.3 \%$ less energy consumption than in the conventional system. It is noted that the compressor and DX evaporator VAV fan power consumptions for the LPA system are less than those for the conventional system while the air-cooled condenser VAV fan power usage is higher than that for the conventional system. The average energy savings potential of the proposed design for the compressor and evaporator fan are respectively $26.5 \%$ and $3.6 \%$ while condenser fan power consumption increases by $4.8 \%$. The reason is that the temperature reduction of the refrigerant entering the condenser yields in a temperature decrease of the refrigerant leaving the condenser, i.e. refrigerant subcool temperature at the condenser outlet is increased. Therefore, enthalpy of the refrigerant entering the evaporator is reduced to increase refrigeration effects, and in turn, the system COP. This causes more heat transfer in the evaporator to decrease the supply air temperature, thus providing building cooling demand to slightly reduce the supply air flow rate, hence to result in less power consumption of the supply fan. Increasing the refrigeration effect also leads to more heat exchange between air and refrigerant in the evaporator. Additional heat absorbed by the refrigerant, however, results in a slight increase in the heat rejected by the condenser to the ambient air, which tends to increase slightly power consumption of the condenser fan. Overall, the total energy usage for each summer month can be obtained by summation of the whole system's energy consumption in each working hour. Figure 11 shows simulation results for the average energy consumption of the conventional and LPA systems and compares it in each summer month. It can be seen that the power consumption of the LPA system is significantly less than that of the conventional plant.

\section{Conclusion}

We have presented a promising technique for energy efficiency improvement in DX air conditioning system by using liquid pressure amplification.

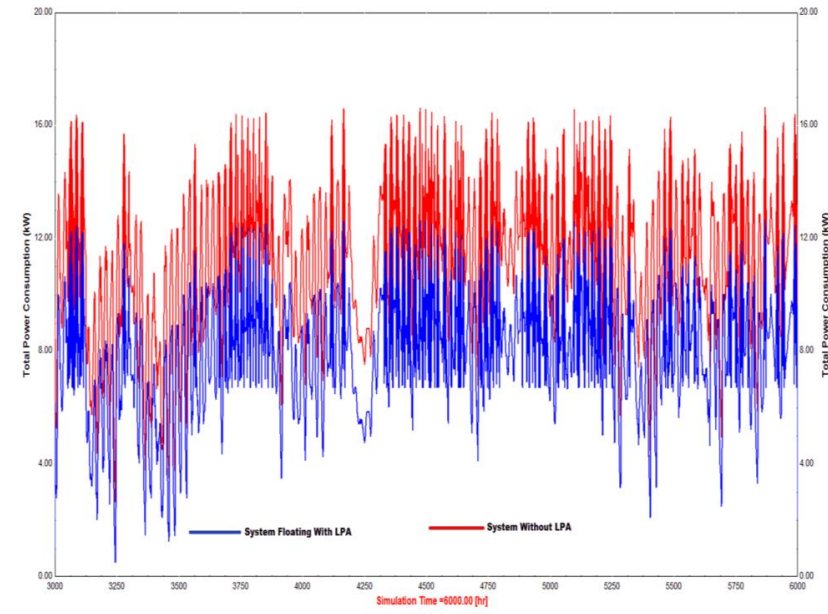

Figure 10. Hourly energy consumption

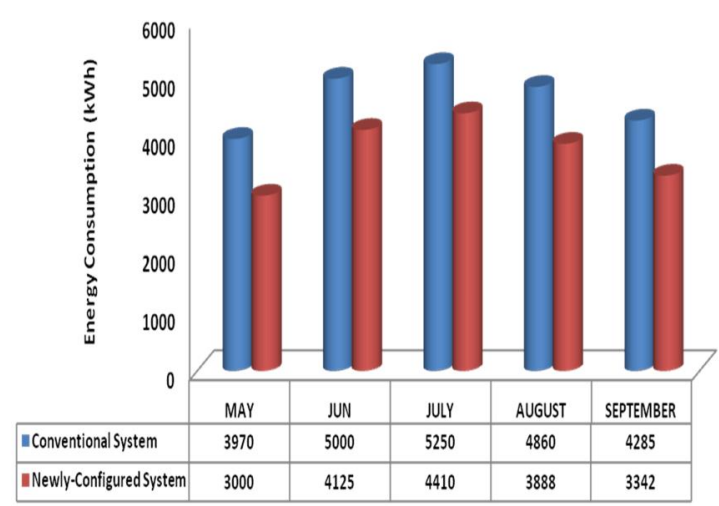

Figure 11. Monthly energy consumption

The simulation-empirical method has been applied for system modelling. The obtained models are validated and used for performance prediction. Simulation results show that by allowing temperature and pressure to fluctuate within the condenser, the reconfigured DX air-conditioning systems with LPA consume less electricity. The method can be used on DX systems that operate with fixed head pressure control. LPA devices can be fitted to new or existing systems. Results showed that the LPA approach is more effective when ambient temperature is falling. The proposed system can save electricity around $25.3 \%$ in average.

\section{Nomenclature}

$\begin{array}{ll}A & \text { area }\left(\mathrm{m}^{2}\right) \\ A U & \text { overall heat transfer coefficient }\left(\mathrm{kW} /{ }^{\circ} \mathrm{C}\right) \\ C_{p} & \text { heat capacity }\left(\mathrm{kJ} /\left(\mathrm{kg}^{\circ} \mathrm{C}\right)\right) \\ D & \text { centre-to-centre spacing between fins } \\ & (\mathrm{m}) \\ d & \text { diameter }(\mathrm{m})\end{array}$




\begin{tabular}{|c|c|}
\hline$d_{c}$ & fin collar outside diameter (m) \\
\hline$e$ & specific cost $(\$ / \mathrm{kg})$ \\
\hline$f$ & friction factor \\
\hline$G$ & mass flux $\left(\mathrm{kg} / \mathrm{m}^{2} \mathrm{~s}\right)$ \\
\hline$h$ & enthalpy $(\mathrm{kJ} / \mathrm{kg})$ \\
\hline HTS & horizontal tube spacing (m) \\
\hline$j$ & Colburn factor \\
\hline$k$ & thermal conductivity $\left(\mathrm{kW} / \mathrm{m}^{\circ} \mathrm{C}\right)$ \\
\hline$M$ & $\operatorname{mass}(\mathrm{kg})$ \\
\hline$m$ & standard extended surface parameter \\
\hline$\dot{m}$ & mass flow rate $(\mathrm{kg} / \mathrm{s})$ \\
\hline$N_{\text {row }}$ & number of rows \\
\hline$N u$ & Nusselt number \\
\hline$P$ & power consumption $(\mathrm{kW})$ \\
\hline$p_{\text {dis }}$ & discharge pressure $(\mathrm{kPa})$ \\
\hline$p_{\text {suc }}$ & suction pressure $(\mathrm{kPa})$ \\
\hline$p_{f}$ & fin pitch \\
\hline $\operatorname{Pr}$ & Prandtl number \\
\hline$Q$ & heat transfer capacity $(\mathrm{kW})$ \\
\hline$Q_{b}$ & building cooling load $(\mathrm{kW})$ \\
\hline$r$ & tube inside radius (m) \\
\hline$R_{e q}$ & equivalent radius for circular fin (m) \\
\hline $\operatorname{Re}_{d}$ & $\begin{array}{l}\text { Reynolds number based on tube } \\
\text { diameter }\end{array}$ \\
\hline $\operatorname{Re}_{c}$ & $\begin{array}{l}\text { Reynolds number based on fin collar } \\
\text { outside diameter }\end{array}$ \\
\hline$T$ & temperature $\left({ }^{\circ} \mathrm{C}\right)$ \\
\hline$t$ & thickness of fins (m) \\
\hline$\Delta T_{m}$ & mean temperature difference \\
\hline$V$ & air flow rate $\left(\mathrm{m}^{3} / \mathrm{s}\right)$ \\
\hline$V_{D}$ & $\begin{array}{l}\text { displacement volume of the compressor } \\
\left(\mathrm{m}^{3} / \mathrm{s}\right)\end{array}$ \\
\hline$V T S$ & vertical tube spacing $(\mathrm{m})$ \\
\hline$\vartheta_{s u c}$ & $\begin{array}{l}\text { specific volume of the refrigerant at the } \\
\text { compressor inlet }\left(\mathrm{m}^{3} / \mathrm{kg}\right)\end{array}$ \\
\hline$W_{\text {in }}$ & $\begin{array}{l}\text { electrical power consumption of the } \\
\text { compressor }(\mathrm{kW})\end{array}$ \\
\hline$x$ & vapor quality \\
\hline$\alpha$ & Heat transfer coefficient $\left(\mathrm{kW} / \mathrm{m}^{2}{ }^{\circ} \mathrm{C}\right)$ \\
\hline$\rho$ & density $\left(\mathrm{kg} / \mathrm{m}^{3}\right)$ \\
\hline$\gamma$ & polytropic index of the refrigerant vapor \\
\hline$\sigma$ & $\begin{array}{l}\text { ratio of minimum free flow area and } \\
\text { frontal area }\end{array}$ \\
\hline$\eta_{\text {comp }}$ & total efficiency of the compressor \\
\hline$\eta_{v}$ & volumetric efficiency of the compressor \\
\hline$\eta_{o}$ & surface effectiveness \\
\hline$\eta_{f}$ & fin efficiency \\
\hline$\phi$ & circular fin efficiency parameter \\
\hline
\end{tabular}

$\begin{array}{ll}\text { Subscripts } & \\ a & \text { air } \\ A l & \text { aluminium } \\ A R & \text { aspect ratio } \\ a v g & \text { average } \\ a m b & \text { ambient } \\ b & \text { bare tube } \\ \text { comp } & \text { compressor } \\ \text { con } & \text { condenser } \\ \text { cond } & \text { condensing } \\ \text { Cu } & \text { Copper } \\ \text { dis } & \text { discharge } \\ e v a & \text { evaporator } \\ f & \text { fin } \\ f r & \text { frontal } \\ h r & \text { heat rejection } \\ i & \text { inlet, inner } \\ l & \text { liquid } \\ \text { max } & \text { maximum } \\ \text { min } & \text { minimum } \\ o & \text { outlet, outer } \\ r & \text { refrigerant } \\ \text { sat } & \text { saturated } \\ \text { sh } & \text { superheated } \\ \text { suc } & \text { suction } \\ \text { sup } & \text { supply } \\ t p & \text { two-phase } \\ w & \text { wall } \\ & \end{array}$

\section{References}

[1] Council of Australian Governments, Guide to Best Practice Maintenance and Operation of HVAC Systems for Energy Efficiency. Department of Climate Change and Energy Efficiency, Australia, 2012.

[2] Chan KT. and Yu FW. Applying condensingtemperature control in air-cooled reciprocating water chillers for energy efficiency. Applied Energy, 72: 565-581, 2002.

[3] Vakiloroaya V., Ha Q.P. and Skibniewski M. Modeling and experimental validation of a solarassisted direct expansion air conditioning system. Energy and Buildings, 66: 524-536, 2013.

[4] Yu F.W. and Chan K.T. Improved energy performance of air-cooled chiller system with mist-pre-cooling mist improvement on air-cooled chillers. Applied Thermal Engineering, 31: 537544, 2011.

[5] Vakiloroaya V., Ha Q.P. and Samali B. Energyefficient HVAC systems: Simulation-empirical modeling and gradient optimization, Automation in Construction, 31: 176-185, 2013. 
[6] Wang X., Hwang Y. and Radermacher R. Investigation of potential benefits of compressor cooling, Applied Thermal Engineering. 28: 17911797, 2008.

[7] Sarntichartsak P. and Thepa S. Modeling and experimental study on the performance of an inverter air conditioner using R410A with evaporatively cooled condenser, Applied Thermal Engineering, 51: 597-610, 2013.

[8] Arias J. and Lundqvist P. Heat recovery and floating condensing in supermarkets, Energy and Buildings, 38: 73-81, 2006.

[9] TRNSYS software. A transient system simulation program, Version 16 (2006). Wisconsis-Madison University, USA.

[10] Schmidt T.E. Heat transfer calculations for extended surfaces. Refrigeration Engineering, 351$357,1949$.

[11] Saechan P. and Wongwises S. Optimal configuration of cross flow plate finned tube condenser based on the second law of thermodynamics. International Journal of Thermal Sciences, 47 (11): 1473-1481, 2008.

[12] Shan M.M. A general correlation for heat transfer during film condensation inside pipes. International Journal of Heat and Mass Transfer, 22 (4): 547-556, 1979.

[13] Dittus F.W. and Boelter L.M.K. Heat transfer in automobile radiators of the tubular type. In: Publication in Engineering, vol. 2, University of California, Berkeley, CA, p. 443, 1930.

[14] McQuiston F. and Parker J. Heating, Ventilation and Air Conditioning Analysis and Design, 4th ed., John Wiley and Sons, Inc. New York, p. 636, 1994.

[15] Wang C.C., Chi K.Y. and Chang C.J. Heat transfer and friction characteristics plain fin-and-tube heat exchangers. Part II: Correlation. International Journal of Heat and Mass Transfer, 43 (15): 26932700, 2000.

[16] ASHRAE Handbook Fundamentals, American Society of Heating, Refrigerating and AirConditioning Engineers, Atlanta, GA, USA, 2009.

[17] Vakiloroaya V., Samali B., Maddadnia J. and Ha Q.P. Component-wise optimisation for a commercial central cooling plant. Proc. 37th Annual Conference on IEEE Industrial Electronics Society, 2769-2774, Melbourne, Australia, 2011.

[18] Minitab User's Guide Release 16, Minitab Inc. State College, PA, USA, 2010. 